\title{
ANALISIS PROBABILISTIC FRACTURE MECHANICS PADA EVALUASI KEANDALAN BEJANA TEKAN REAKTOR SECARA 3-D
}

\author{
Entin Hartini, Roziq Himawan, Mike Susmikanti \\ Pusat Teknologi dan Keselamatan Reaktor Nuklir - BATAN \\ Kawasan Puspiptek Serpong Gd.80, Tangerang Selatan, Banten 15314 \\ e-mail: entin@batan.go.id
}

(Naskah diterima: 05-01-2018, Naskah direvisi: 19-01-2018, Naskah disetujui: 01-02-2018)

\section{ABSTRAK}

ANALISIS PROBABILISTIC FRACTURE MECHANICS PADA EVALUASI KEANDALAN BEJANA TEKAN REAKTOR SECARA 3-D. Analisis integritas material sangat diperlukan pada Reactor Pressure Vessel (RPV). Komponen tersebut merupakan pressure boundary yang berfungsi untuk mengungkung material radioaktif. Adanya retak pada dinding dapat mempengaruhi integritas RPV tersebut. Penelitian ini bertujuan melakukan analisis fracture mechanics menggunakan model probabilistik untuk evaluasi keandalan RPV. Model probabilistik digunakan untuk pendekatan karakter random dari kuantitas input seperti sifat mekanik material dan lingkungan fisik. Karakter random dari kuantitas input menggunakan teknik sampling berdasarkan probability density function. Material yang digunakan pada RPV adalah baja feritik (SA 533). Analisis fracture mechanics dilakukan berdasarkan metode elemen hingga (FEM) menggunakan perangkat lunak MSC MARC. Output dari MSC MARC adalah nilai $J$ integral untuk mendapatkan nilai stress intensity factor (SIF) pada evaluasi keandalan bejana tekan reaktor 3D. Hasil perhitungan menunjukan bahwa SIF probabilistik lebih dulu mencapai nilai batas fracture toughness dibanding SIF deterministik. Nilai SIF yang dihasilkan dengan metode probabilistik adalah 95,8 MPa $\mathrm{m}^{0,5}$, sedangkan dengan metode deterministik adalah $91,8 \mathrm{MPa} \mathrm{m}^{0,5}$, rasio crack (a/c) semakin kecil akan dihasilkan nilai SIF yang semakin besar.

Kata kunci:Probabilistic fracture mechanics, bejana tekan, 3-D. 


\section{ABSTRACT}

PROBABILISTIC FRACTURE MECHANICS ANALYSIS FOR THE EVALUATION OF REACTOR PRESSURE VESSEL RELIABILITY USING 3-D MODEL. Material integrity analysis is required for the reactor pressure vessel (RPV). The component is the pressure boundary that serves to contain radioactive materials. The presence of cracks on the walls can affect the integrity of the RPV. The objective of this studyis to analyze fracture mechanics using probabilistic models for the evaluation of RPV reliability. Probabilistic models are used as an analysis approach for random character of input quantities such as the mechanical properties of materials and the physical environment. The random character of input quantities was obtained by sampling technique base on probability density function. The material used in this study was ferritic steel (SA 533). Fracture mechanics analysis was performed by Finite Element Method (FEM) with MSC $M A R C$ software. The outputs of MSC MARC, which is of $J$ integral values, were converted into stress intensity factor (SIF) for evaluating the reliability of RPV in $3 D$ model. It is found thatthe calculation resulted from the SIF by probabilistic method reaches a limit value of fracture toughness earlier tha nthe SIF by deterministic method. The SIF generated by probabilistic method is $95,8 \mathrm{MPa} \mathrm{m}^{0.5}$, while the SIF generated by deterministic method is $91,8 \mathrm{MPa} \mathrm{m}^{0.5}$, where lower ratio value of $(a / c)$ will produce greater value of SIF.

Keywords: Probabilistic fracture mechanics, pressure vessels, 3-D. 


\section{PENDAHULUAN}

Bejana tekan merupakan komponen yang dalam pengoperasiannya menerima internal pressure relatif besar. Pada instalasi Pembangkit Listrik Tenaga Nuklir (PLTN), terdapat bejana tekan berukuran besar seperti bejana tekan reaktor dan berukuran kecil seperti pin bahan bakar nuklir. Dua bejana tekan di dalam reaktor ini merupakan pressure boundary yang berfungsi sebagai pengungkung lapis dua dan tiga terhadap bahan radioaktif yang dihasilkan pada proses reaksi berantai. Oleh karena itu, integritas Reactor Pressure Vessel (RPV) harus terjamin keselamatannya. Integritas RPV dapat berpengaruh dengan adanya crack, sehingga perlu dilakukan evaluasi keandalan material menggunakan metode fracture mechanic[1-3].

Model persamaan dan kondisi awal sistem tidak diketahui secara akurat sehingga berpengaruh terhadap prediksi prilaku sistem dari kemungkinan kegagalan. Kondisi ini mengakibatkan keamanan mutlak dari struktur material tidak bisa dijamin, karena tidak menggambarkan sifat material secara akurat dan ketidakpastian kondisi pembebanan. Oleh karena itu digunakan model probabilistik untuk menghitung margin keselamatan dengan memperhitungkan ketidakpastian input yang berpengaruh terhadap nilai output [1-2,4-7].

Pada perhitungan fracture mechanics untuk J Integral dari RPV, material properties dan internal presure adalah faktor ketidakpastian dan merupakan random input. Oleh karena itu, penilaian keandalan RPV harus dilakukan dengan model probabilistik. Tujuan penelitian ini adalah untukmenetukan dan mengevaluasi keandalan bejana tekan reaktor Pressure Water Reactor (PWR) dengan melakukan analisis fracture mechanics dengan model probabilistik. Pada penelitian sebelumnya telah dilakukan analisis ketidakpastian input pada fracture mechanic untuk mengevaluasi keandalan RPV tipe PWR 2-D dengan beban internal pressure[8,9]. Penelitian lanjutan ini dilakukan untuk mengevaluasi keandalanRPV dengan model dinding bejana tekan sebagai plate 3-D, yang terdapat crackfront ke arah radial. Model 3-D dipilih karena mendekati keadaan realitas dan perhitungannya lebih teliti. Penggunaan rasio crack adalah untuk menguji panjang dan kedalaman kritis [7,14-15].

Bahan dari dinding bejana tekan yang dievaluasi adalah baja feritik (SA 533). Perhitungan $J$ integral dilakukan dengan menggunakan perangkat lunak MSC MARC $[16,17]$. Analisis probabilistik pada $\mathrm{J}$ integral dilakukan pada ketidakpastian input untuk pembebanan dan material properties menggunakan teknik sampling berdasarkan probability density function (PDF) [11-13]. Hasil akhir dari penelitian ini adalah nilai stress intensity factor untuk mengevaluasi keandalan bejana tekan reaktor PWR. Output dari MSC MARC adalah nilaiJintegral, yang kemudian diubah menjadi stress intensity factor (SIF) untuk mengevaluasi keandalan RPV 3-D [8,17-18].

Telah banyak model komputasi memberikan korespondensi yang baik antara nilai-nilai hasil perhitungan dan pengukuran. Fracture mechanics merupakan suatumetode untuk menilai kekritisan cacat dalam struktur serta dapat menggambarkan hasil secara kuantitatif trade-off antara tekanan, ketangguhan material, dan ukuran cacat. Proses evaluasi dengan cara metode fracture mechanicselastis linear tidak dapat dianggap sebagai nilai numerik konstan secara deterministik karena karakter random. Pendekatan untuk mengambil karakter random dari kuantitas input ke dalam suatu perhitungan (karakteristik material, geometri, dan efek pembebanan) mengarah ke aplikasi prinsip dan metode perhitungan dari model probabilistik [2,4-5].

Simulasi teknik sampling digunakan untuk melakukan analisis ketidakpastian input berdasarkan model probabilistik. 
Simulasi sampling memerlukan beberapa persyaratan, (1) definisi variabel random dan karakteristik probabilistik dalam PDF, (2) generasi variabel random dan evaluasi untuk semua set variabel random serta informasi untuk jumlah atau banyaknya simulasi[11-13].

Adanya retak struktur di bawah ketidakpastian mechanic, geometri dan beban random dilambangkan dengan vektor acak $X$ dimensi $N$, dimana komponen dari vektor $X$ adalah $X_{1}, X_{2}, \ldots, X_{N}$ dengan karakterisasi ketidakpastian pada beban dan material properties. Jika ukuran crack $a$, elastis modulus $E$, besarnya stress $\sigma^{\infty}$ dan fracture toughness pada crack inisiasi $K_{I C}$, dimodelkan sebagai variabel input random, maka $X=g\left(a, E, \sigma^{\infty}, K_{I C}\right) . K_{I C}$ adalah nilai kemampuan komponen untuk menahan perambatan crack. Stress intensity factor $\left(K_{1}\right)$, dapat dihitung dengan menggunakan metode elemen hingga. Struktur dikatakan gagal jika $K_{l}>K_{I C}$. Persyaratan ini tidak dapat dipenuhi dengan pasti, karena $K_{l}$ tergantung kepada vektor input dari vektor random $X$, dan $K_{I C}$ merupakan variabel random [19].

Random generasi untuk input beban dan material properties berdasarkan PDF mengikuti persamaan $1[8,13]$.

$$
x_{i}^{j}=F_{j}^{-1}\left(\frac{\pi_{j}^{(i)}-\zeta_{j}^{i}}{n}\right)
$$

Dimana $\pi_{j}$ uniform random permutasi independen untuk bilangan bulat $\{1,2, \ldots, \mathrm{n}\}$ dan $\zeta_{i}^{j}$ adalah $\cup[0,1]$ independen dari nilai random untuk $\pi_{j}$.

Energi rilis non linier front carck untuk 3-D dinyatakan sebagai $J$ integral semi elliptic. Nilai $J$ Integral dievaluasi di sekitar frontcrack dalam bentuk nilai stress. $J$ integral dapat dimodifikasi secara numerik atau melalui metode elemen hingga. Jintegralrerata tertimbang untuk crack front di sekitar segmen $\Delta \mathrm{L}$ dinyatakan dalam persamaan 2[7].

$$
J \Delta L=\int_{\Delta L} J(\mu) q d \mu
$$

dimana $q$ adalah rasio dari $\Delta L / \Delta a, \Delta L$ adalah panjang spesimen dan $\Delta a$ adalah kedalaman crack. Sementara itu, $J(\mu)$ merupakan nilai pointwise dari integral path yang mengandung ujung crack, dan $q$ adalah fungsi tertimbang. Dalam mekanika fraktur, perambatan retak eliptic diidentifikasi oleh $K_{l} . K_{l}$ adalah besaran yang menunjukan besarnya medan stress elastis. Analisis 3-D menunjukkan bahwa $K_{l}$ berhubungan linier terhadap stress dan merupakan akar dari panjang karakteristik. Panjang karakteristik merupakan panjang crack. $K_{/}$diberikan oleh persamaan 3[7].

$$
K_{I}=\sigma \sqrt{\pi a} \cdot f(a / c)
$$

di mana a adalah panjang crack, $\sigma$ merupakan nominal stress, $c$ adalah lebar spesimen, $(a / c)$ adalah ratio dari crack, sedangkan $f(a / c)$ adalah fungsi dari rasio kedalaman crack dan lebar dari spesimen.

Hubungan nilai $K_{l}$ dengan nilai $J$ Integral dinyatakan pada persamaan 4 [8,17-19]

$$
K_{I}=\sqrt{\frac{E J}{1-v^{2}}}
$$

dimana $E$ adalah Modulus young, $v$ merupakan poison ratio, dan $J$ adalah nilai dari $\mathrm{J}$ integral.

\section{METODOLOGI}

MSC MARC digunakan untuk melakukan perhitungan fracture mechanic bejana tekan PWR. Perhitungan dilakukan secara deterministik dan probabilistik dengan carasimulasi menggunakan MSC MARC. Langkah yang dilakukan adalah pre-processor yang mendefinisikan geometri dan membuat meshing. Langkah berikutnya dilakukanadalah menentukan sifat material, menentukan posisi retak awal dan kondisi batas, mensimulasikan retak dan memilih tampilan yang akan dianalisis ( $\mathrm{J}$ integral).

Sampel yang digunakan adalah plate (3-D) dinding bejana tekan reaktor PWR dari baja feritik bahan (SA 533) dengan panjang 
$5000 \mathrm{~mm}$ dan lebar $1000 \mathrm{~mm}$ [8]. Poison ratio adalah 0,3 dan modulus Young $(E)$ adalah $192 \times 10^{3} \quad \mathrm{MPa}[8]$. Beban didistribusikan dalam komponen yang bekerja pada dinding dengan tekanan di $50 \mathrm{MPa}$. Tekanan internal selama operasi reaktor adalah $14 \mathrm{MPa}-17 \mathrm{MPa}$. Retak awal permukaan pada simulasi ini dianalisis menggunakan rasio depth crack (a) dan length crack (c) sebesar 0,33; 0,50;0,67; 1. Model simulasi (plate) 3-D dari bejana tekan reaktor ditunjukkan pada Gambar 1[17].

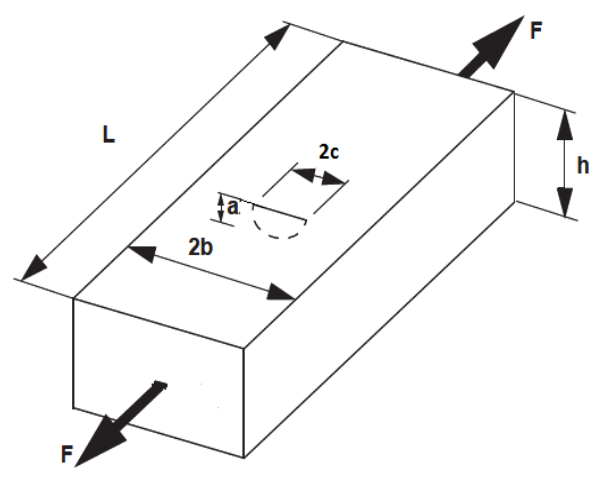

Gambar 1. Geometri plate 3-D

dimana:

a : panjang crack,

$\mathrm{c}$ : kedalaman crack

b : lebar plate

$\mathrm{h}$ : tebal plate

$\mathrm{L}$ : panjang plate

$\mathrm{F}$ : beban

Model crack semi elliptical 3 dimensi digunakan untuk analisis plate. Model eliptical crack dalam analisis ini adalah model seperempat elips. Model crack seperempat eliptical dibagi dari titik pusat sepanjang sumbu $X$ dan $Y$. Model tersebut ditunjukan pada Gambar 2 [14-15].Pada perhitungan $J$ integral model probabilistik, input data dari sifat material yaitu modulus elastisitas dan parameter pembebanan melibatkan ketidakpastian. Teknik sampling berdasarkan PDF digunakan untuk mengakomodasi model ketidakpastian dari parameter yang terkait dalam perhitungan $[8,17-19]$. Setelah nilai $J$ integral dari MSC MARC diperoleh, tahap selanjutnya adalah menghitung $K_{l}$ dan membandingkannya dengan $K_{I C}[17]$.

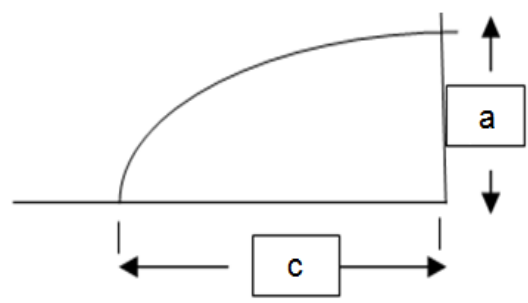

$a=$ dimensi kedalaman crack $c=$ dimensi panjang crack

Gambar 2. Dimensi dari seperempat elips

\section{HASIL DAN PEMBAHASAN}

Hasil simulasi perhitungan $J$ integral diperoleh dengan MSC MARC pada pemodelan 3D dengan adanya initial crack pada geometri arah radial ditampilkan pada Gambar 3 dan 4. Hasil $\mathrm{J}$ integral diperoleh sebesar 0,02996 merupakan hasil simulasi $\mathrm{J}$ integral deterministik dengan rasio crack $(\mathrm{a} / \mathrm{c})=3 / 3$. 


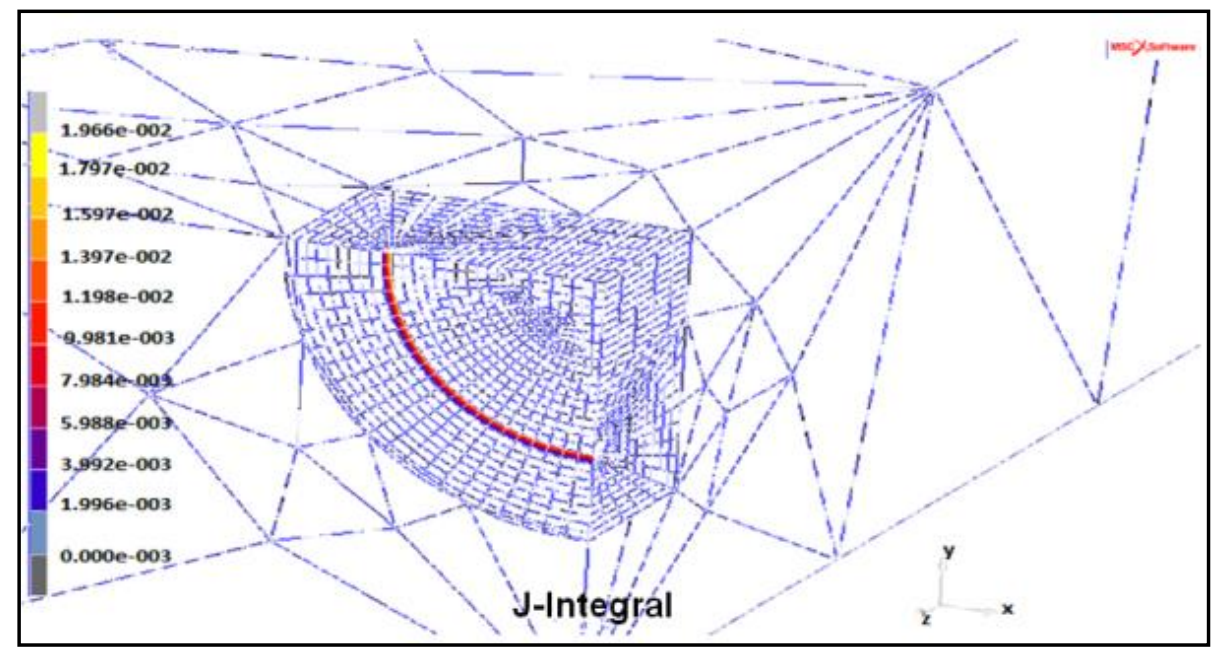

Gambar 3. Permukaan crack untuk rasio $\operatorname{crack}(a / c=3 / 3)$

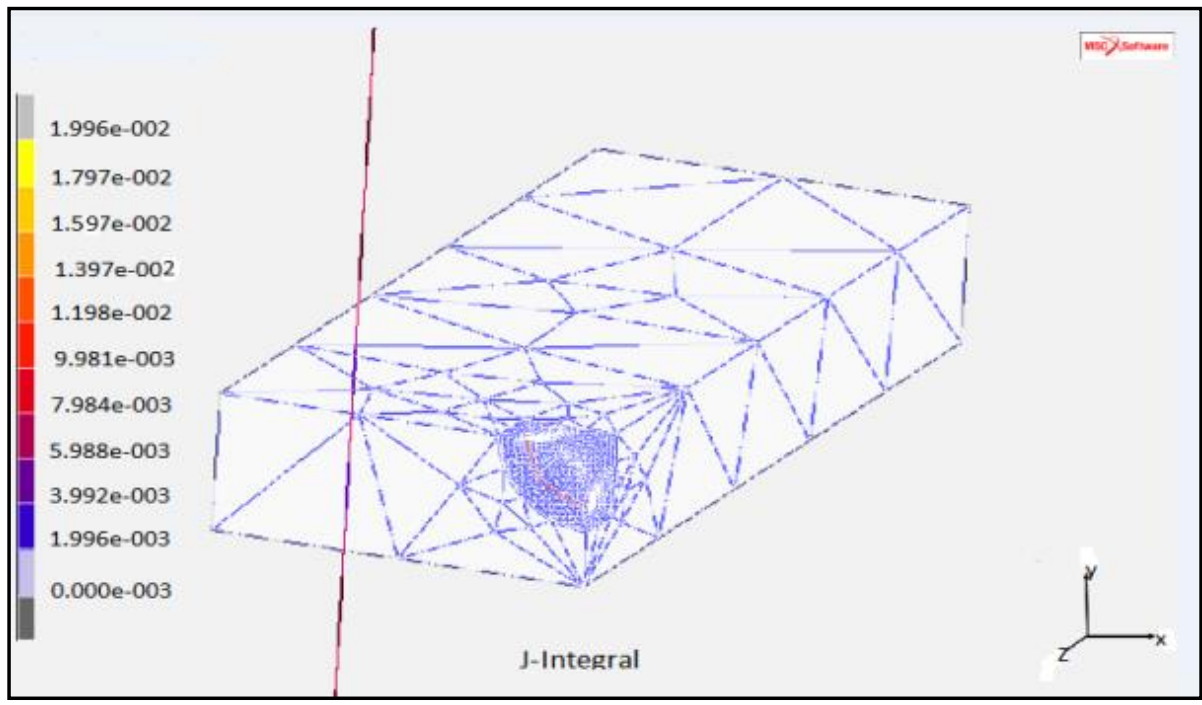

Gambar 4. J Integral untuk rasio $\operatorname{crack}(\mathrm{a} / \mathrm{c}=3 / 3)$

Hasil perhitungan J Integral secara pobabilistik pada MSC MARC

Dalam perhitungan $\mathrm{J}$ integral secara probabilistik, nilai modulus dan beban pada input data MSC MARC diganti dengan nilainilai generasi sampel berdasarkan PDF dari masing-masing variabel. Hasil simulasi perhitungan $\mathrm{J}$ integral secara probabilistik dengan melakukan generasi sampel sebanyak 20 dengan nomer sampel 1 sampai dengan 20, dimana PDF untuk modulus elaticity berdistribusi normal dan pembebanan berdistribusi uniform dengan rasio $\operatorname{crack}(\mathrm{a} / \mathrm{c})=1 / 3,2 / 3$ dan $3 / 3$ disajikan pada Gambar 5, 6 dan 7.

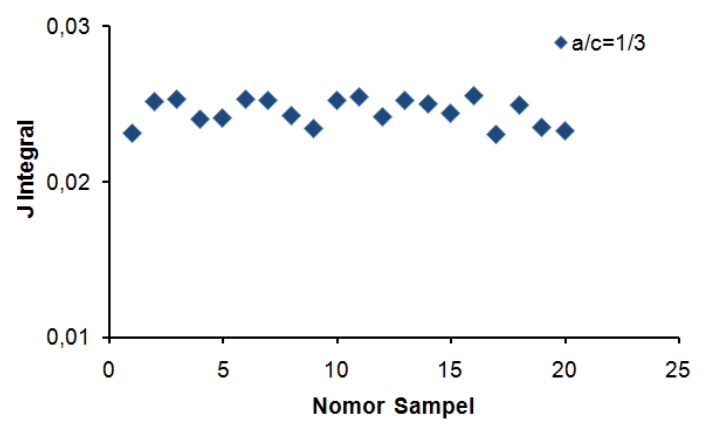

Gambar 5. J-Integral 20 sampel dengan rasio crack $1 / 3$ 


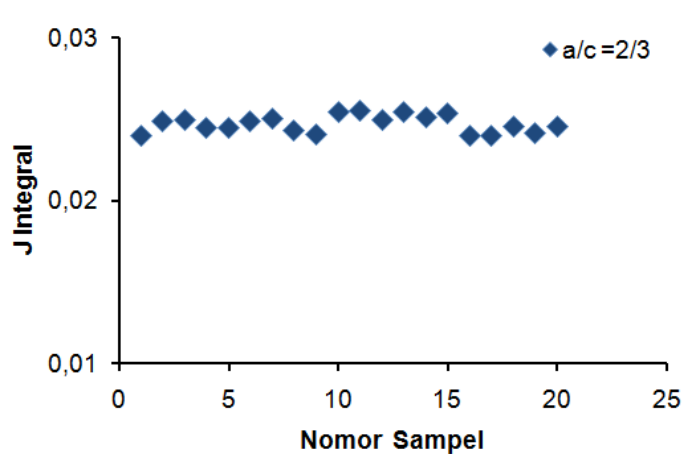

Gambar 6. J Integral 20 sampel dengan rasio crack $2 / 3$.

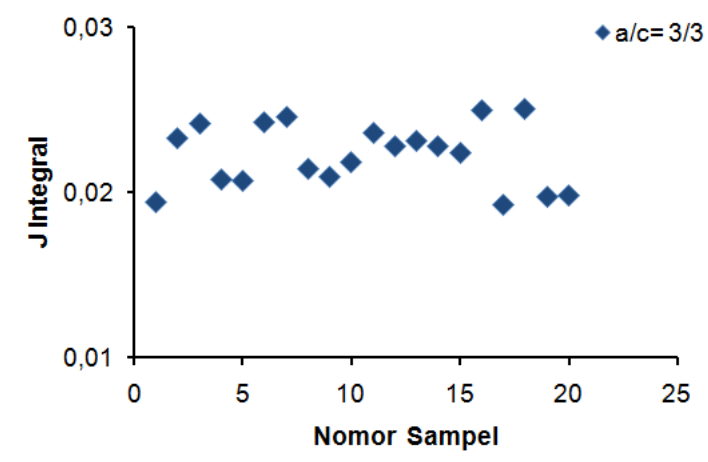

Gambar 7. J integral 20 sampel dengan rasio crack $(3 / 3)$.

Berdasarkan hasil $\mathrm{J}$ integral probabilistik untuk rasio crack 1/3,1/2 dan $3 / 3$ ditunjukkan pada Gambar 5, 6 dan 7, nilai J integral probabilistik dihitung berdasarkan rerata dari nilai tersebut.

Hasil perhitungan $\mathrm{J}$ integral secara deterministik dan probabilistikdengan variasi rasio crack $(1 / 3,1 / 2,2 / 3,3 / 3)$ dan hasil perhitungan SIF secara deterministik dan probabilistikmenggunakan MSC MARC ditunjukan pada Gambar 8 dan 9.

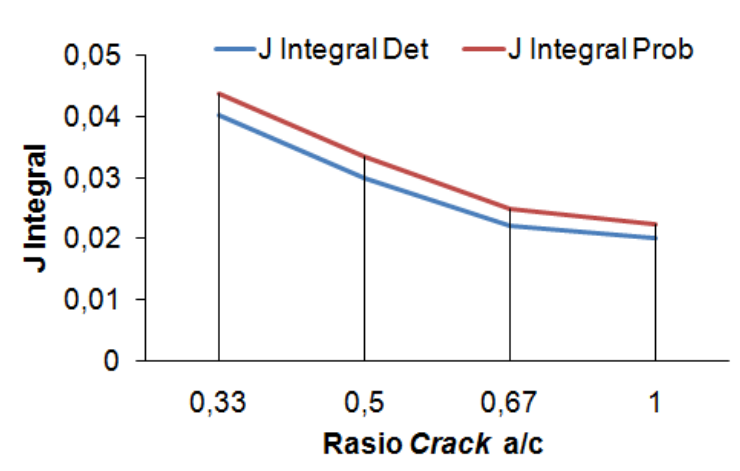

Gambar 8. J Integral deterministik dan probabilistik dengan rasio crack $(\mathrm{a} / \mathrm{c})$.

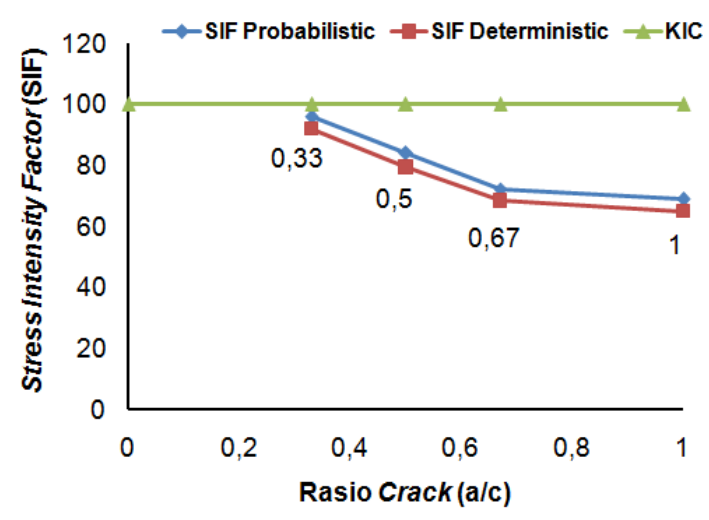

Gambar 9. SIF deterministik dan probabilistik dengan rasio crack $(\mathrm{a} / \mathrm{c})$.

Hasil perhitungan $\mathrm{J}$ integral dan SIF yang ditampilkan pada Tabel 3 sesuai dengan rumus (3) dan (4). Dimana nilai SIF tergantung dari fungsi kedalaman crack dan panjang crack. Berdasarkan Gambar 8 dan Tabel 1, rasio crack (a/c) semakin kecil maka nilai $\mathrm{J}$ integral dan SIF semakin besar. Jika diurutkan hasil nilai $\mathrm{J}$ integral dan stress intensity factor dari besar ke kecil berdasarkan rasio $\operatorname{crack}(\mathrm{a} / \mathrm{c})$ adalah 1/3, 1/2, 2/3 dan 1.

.Tabel 1. J Integral dan SIF Plate3-D

\begin{tabular}{ccccc}
\hline \multirow{2}{*}{ Variabel } & \multicolumn{4}{c}{ Rasio Crack (a/c) } \\
\cline { 2 - 5 } & $1 / 3$ & $1 / 2$ & $2 / 3$ & $3 / 3$ \\
\hline J Integral Deterministik & 0,039 & 0,029 & 0,022 & 0,019 \\
J integral probabilistik & 0,043 & 0,033 & 0,025 & 0,022 \\
SIF Deterministik (SIF Det) (MPa m,5) & 91,844 & 79,266 & 68,254 & 64,895 \\
SIF Probabilistik (SIF Prob) (MPa m,5) & 95,837 & 83,821 & 72,199 & 68,826 \\
\hline
\end{tabular}


Berdasarkan Gambar 8 dan 9 dengan ratio $\operatorname{crack}(\mathrm{a} / \mathrm{c})=1 / 3$, nilai $\mathrm{J}$ integral deterministik $=0,03998$. Dari nilai $\mathrm{J}$ integral $\mathrm{di}$ atas dihitung nilai SIF $\left(K_{l}\right)=91,84411 \mathrm{MPa} \mathrm{m}^{0,5}$. Nilai $\mathrm{J}$ integral probabilistik dengan input modulus elasticity dan pembebanan masing-masing berdistribusi normal dan uniform adalah 0,04353 , diperoleh nilai $\mathrm{SIF}=95,83766 \mathrm{Mpa} \mathrm{m}^{0,5}$. Berdasarkan simulasi tersebut memperlihatkan bahwa SIF probabilistik dengan rasio crack $(\mathrm{a} / \mathrm{c})$ lebih mendekati nilai batas fracture toughness (KIC) $100 \mathrm{MPa} \mathrm{m}^{0,5}$ (tabel mechanical properties material)dibandingkan dengan SIF deterministik.

\section{SIMPULAN}

Hasil perhitungan menunjukan bahwa SIF probabilistik dengan rasio crack (a/c) lebih mendekati nilai batas fracture toughness dibanding SIF deterministik. Pada model 3-D untuk rasio crack $(a / c)$ dengan perbandingan kedalaman crack dan panjang crack lebih kecil maka nilai $\mathrm{J}$ integral dan SIF semakin besar.

\section{UCAPAN TERIMAKASIH}

Penulis mengucapkan terimaksih untuk alokasi dana penelitian inipada DIPA PTKRN -BATAN 2016, Dr Syaeful Bakhri, yang telah menugaskan penelitian ini dalam kegiatan Bidang Teknologi Keselamatan Reaktor, PTKRN - BATAN, 2016.

\section{DAFTAR PUSTAKA}

[1] B. Y. Chen, C. C. Huang, H. W. Chou, H. C. Lin, R. F. Liu, T. L. Weng, and H. J. Chang, "Reactor pressure vessel integrity assessment by probabilistic fracture mechanics a plant specific analysis," International Journal of Pressure Vessels and Piping, vol.117, pp. 64-69, 2014.

[2] S. Li, H. Zhang, S. Li, Y. Wang, F. Xue, and $X$. Wang, "Probabilistic fracture mechanics analysis of thermally aged nuclear piping in a pressurized water reactor,"Nuclear Engineering and Design, vol. 265, pp. 611-618, 2013.

[3] H. W. Viehrig, E. Altstadt, M. Houska, and M. Valo, "Fracture mechanics characterisation of the beltline welding seam of the decommissioned WWER440 reactor pressure vessel of nuclear power plant Greifswald Unit 4," International Journal of Pressure Vessels and Piping, vol. 89, pp.126-139, 2012.

[4] K. Onizawa, H. Nishikawa, and H. Itoh, "Development of probabilistic fracture mechanics analysis codes for reactor pressure vessels and piping considering welding residual stress,"International Journal of Pressure Vessels and Piping, vol. 87, pp. 2-10, 2010.

[5] S. Sankararaman, Y. Ling, and S. Mahadevan, "Uncertainty quantification and model validation of fatigue crackgrowth prediction, "Engineering Fracture Mechanics, vol. 78, pp. 14871504, 2011.

[6] Y. Yamashita and T. Hirano, "Scatter band prediction for fracture toughness of specimens with prior load," Engineering Fracture Mechanics, vol. 86, pp. 73-89, 2012.

[7] F. G. Albuixech, G. Qian, and M. Niffenegger, "Integrity analysis of reactor pressure vessels subjected to pressurizedthermal shocks by XFEMV, "Nuclear Engineering and Design, vol. 275, pp. 336-343, 2014.

[8] E. Hartini, R. Himawan, dan M. Susmikanti, "Uncertainty Analysis on Fracture Mechanics Assessment of Reactor Pressure Vessel: (2D) Subjected to Internal Pressure," Tri Dasa Mega, vol. 18, no.2, 2016.

[9] M. Susmikanti, R. Himawan, A. Hafid, dan E. Hartini, "Evaluation On Mechanical Fracture of PWR Pressure Vessel and Modelling Based on Neural 
Network", Tri Dasa Mega, vol.18, no.2, 2016.

[10] R. Himawan dan M. Susmikanti, "Circumferential Inhomogenity Analysis In G.A Siwabessy Reactor's Primary Cooling Pipe," Tri Dasa Mega, vol.18, no. 3, 2016.

[11] S. Sankararaman, Y. Ling, and S. Mahadevan, "Uncertainty quantification and model validation of fatigue crack growth prediction," Engineering Fracture Mechanics, vol. 78, pp. 14871504, 2011.

[12] S. Sankararaman, Y. Ling, S. Mahadevan, D. Kancev, G. Zerovnik, and M. Cepin, "Uncertainty analysis in the nuclear industry: Analytical unavailability modelling incorporating ageing of safety components," Journal of Loss Prevention in the Process Industries, vol. 25, pp. 643-649, 2012.

[13] M. Vorechovsky, "Hierarchical Refinement of Latin Hypercube Samples, Computer-Aided," Civil and Infrastructure Engineering, vol. 29, pp. 1-18, 2014.

[14] R. H. A. Latiff and F. Yusof, "Method to Model Semi Eliptical Surface," Journal of Engineering and Applied Sciences, vol. 11, no. 1, pp. 222-228, 2016.
[15] A. Sivasubramanian and G. Arunkumar, "Fracture Analysis of Three Dimensional Elliptical Crack for Al7075T651 Plate with Holes," Indian Journal of Science and Technology, vol. 9, no. 34, pp. 1-8, 2016.

[16] MSC Software, "User's Guide MARC", USA, 2012.

[17] A. Gopichand, Y. Srinivas, and A.V.N.L. Sharma, "Computation Of Stress Intensity Factor Of Brass Plate With Edge Crack Using J-Integral Technique," International Journal of Research in Engineering and Technology, vol. 1, pp. 261-266, 2012.

[18] M. J. Jhung, S. H. Kim, Y. H. Choi, S. Jung, J. M. Ki, J. H. Kim, et.al, "Structural integrity assessment of reactor pressure vessels during pressurized thermal shock," Journal of Mechanical Science and Technology vol. 22, pp. 1451-1459, 2008.

[19] M. R. M. Akramin, A. Zulkifli, A. K. Amirruddin, N. A. Alang, and M. S. Jadin, "Hybrid Finite Element and Monte Carlo Analysis of Cracked Pipe", National Conference in Mechanical Engineering, 2010, pp. 167-175. 
Vol. 24 No. 1, Februari 2018: 1-72 